\title{
Sustainability of rainwater harvesting system for the domestic needs: A case of Daugha Village Development Committee, Gulmi, Nepal
}

\author{
R. Dongol, R.C. Bohara and S.R. Chalise \\ Nepal Engineering College, Pokhara University (Affiliated), Lekhnath, Kaski
}

\begin{abstract}
Rainwater Harvesting (RWH) system for the domestic needs in Daugha Village Development Committee (VDC), after its installation in 1996, has become a "unique water culture" with altogether 1,238 water harvesting jars and storage tanks of varied sizes at present in 663 households. The paper presents the sustainability of the RWH implemented 18 years back at the household level of Daugha VDC, Gulmi District. Various participatory tools like household interviews, key informant's interviews and field observation along with water quality test of the stored water were carried out. The sustainability of the rainwater harvesting system was assessed based on the four key sustainability dimensionsTechnical, Socio-environmental, Institutional and Cost recovery. The core factors and sub-factors were given weightage following the Multi Criteria Analysis (MCA) method. Daugha community has accepted RWH as an appropriate and effective alternative to meet the domestic water demand making the systems life savior, where water drudgery was at the peak and mostly women and children shared the responsibility of water management. On an average, 6.35 hours per family per day is saved because of installed RWH system in their homestead which is being utilized in some economic, social and child-care activities by the women. However, the best utilization of saved time for economic growth through various Income Generating Activities (IGAs) and mobilization of local funds to improve income level of the people seems lacking. Similarly, capacity and skills of local people to upgrade and improve their RWH systems have been observed as a gap. RWH systems have imparted very positive effect on sanitation and hygiene front. Significant progress was seen in terms of construction and use of toilets, increased knowledge about the importance of sanitation and hygiene issues, and changes in sanitation and hygiene behavior in the communities. This has resulted in decrease of water borne and water washed diseases recorded in the local sub-health post. These indicators portray the strong technical and socio-environmental acceptance of the system. In contrast to this, the study revealed that institutional and cost-recovery dimensions of sustainability are weaker, which pulls overall sustainability of RWH system under "sustained but at risk" when compared to sustainability ranking practiced by WaterAid.
\end{abstract}

Key words: Rainwater water harvesting, sustainability, multi-criteria method

\section{Introduction}

Millions of people throughout the world do not have access to clean water for domestic purposes (WHO/UNICEF, 2012). In many parts of the world conventional piped water is either absent, unreliable or too expensive. One of the biggest challenges of the $21^{\text {st }}$ century is to overcome the growing water shortage. Population growth all over the world is causing similar problems and concerns of how to supply quality water to all. Much of the water shortages can be relieved, if Rainwater Harvesting (RWH) is practiced more widely. Rainwater harvesting, though an old-age practice, is emerging as a new avenue in water resource development and management due to the recent efforts of both government and

*Corresponding author, email address: robert@nec.edu.np non-governmental organizations to promote water harvesting and groundwater recharge in urban and rural areas (Dey \& Sikka, 2010). RWH is an environmentally sound solution to address issues brought forth by large projects utilizing centralized water management approaches (Julius et al., 2013). Individual rainwater harvesting systems are one of the many tools to meet the growing water demand. Rainwater collected from the roofs of houses and local institutions can make an important contribution to the availability of drinking water. The average annual rainfall data of the nearest rain gauge station of Daugha VDC located in Ridi Bazar of Gulmi District shows 1,330 $\mathrm{mm}$ for the period of last 20 years (DHM, 2014); however, because of the country's geography, the 
most part of received rain quickly flows down to the valleys, catches rivulets and streams to join the big rivers. Because of its feasibility, many agencies today are involved in supporting communities with RWH programs in different parts of the country. Therefore, it is imperative to check the sustainability aspects of those systems. The present study was carried out to assess the sustainability of rainwater harvesting system for the rural communities to meet their domestic water need.

\section{Materials and Methods Study area}

Daugha VDC is situated in the South, remote part of Gulmi District (Fig. 1). It is located between Siddheshwor VDC of Palpa District in the East, Chidika VDC of Arghakhanchi in the West, Kharjyang VDC of Gulmi in the North and Bhuwanpokhari VDC of Palpa in the South. Out of 79 VDCs in Gulmi district, Daugha used to be the most hardship VDC in terms of water supply situation until mid-nineties. Scarcity of water for domestic uses was so severe that people had to spend more than three hours to fetch a pitcher of water (RWSSP, 1995).

\section{Water sources in the VDC: Springs, Kuwas (wells) and Traditional ponds}

Daugha VDC is situated at an altitude of about 1,150 meters from sea level. There are altogether 10 springs (mul) used regularly in the past for drinking water purpose. Many of them are the seasonal sources, which become dry during summer. Only few of them are the perennial ones like Nigata (Hingya) mul, Dharapani mul and Gokule mul of ward numbers 1,5 and 6 respectively. Almost all of them are situated in the lower altitude than the settlements, therefore people need to walk downhill for about 2 hours per trip to fetch water. A very conservative estimate shows that one family of 3-5 members, on an average, needs around 60 liters of water per days for the domestic purpose. That means each family had to make 4 round trips (one pitcher of 15 liters capacity) to the water sources. As the sources are located at a far distance (average round trip time of 2 hours), a huge amount of time about 6-7 hours per day per family on an average has to be devoted for water collection. Based on their responses during household interviews, a simple calculation was made for various categories of families depending upon the distance to the sources or time required for one round trip. This gave an average of 6.5 hours of fetching time per family per day. Apart from the (Mul) springs, people of the study area depend mostly on the water collected in traditional ponds for various domestic needs like; washing, bathing, feeding cattle and also for the community needs like religious events, marriage ceremonies, funeral activities, etc.

\section{Methods}

The study followed both quantitative and qualitative methods. Both types of data, i.e. quantitative data, and the perceptions and experiences of people in terms of qualitative data were collected through household survey conducted in 104 households based on sample size determination formula (Cochran, 1977), key informant interview and field observation. Systematic sampling was adopted to select the households which was divided into each wards based on representative distribution principle with that of the ward households. The study also tried to include the perceptions of both male and female respondents. The rainwater harvesting systems at households were observed thoroughly during the field visit. The observation focused mainly on physical condition of the installed RWH systems, their functioning and level of service delivery, operation and maintenance aspects of the systems, available water quantity and quality, and the overall durability of the systems. This helped validation and cross checking of data gathered from households and the individual person's interviews. Water quality parameters such as temperature, odor,

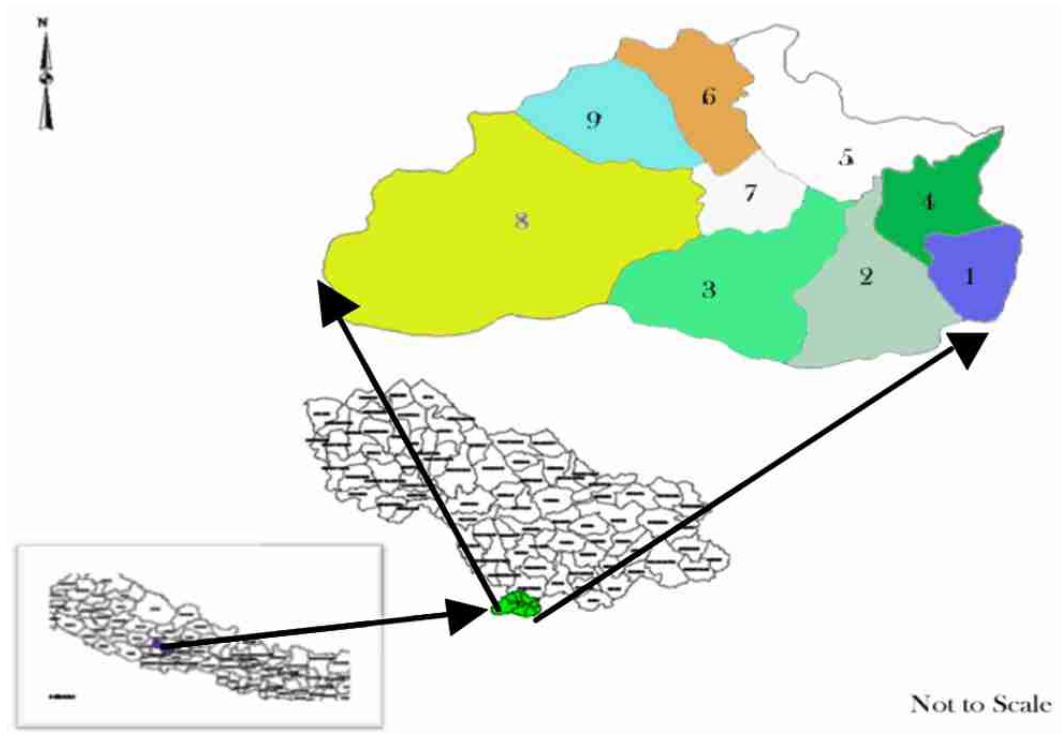

Figure 1 Daugha Village Development Committee (VDC) Gulmi District

\section{橪 TU-CDES}


taste, color, $\mathrm{pH}$, ammonia, iron, hardness, free residual chlorine and coliform bacteria of harvested rainwater were also analyzed with the help of water test field-kit developed by Environment and Public Health Organization (ENPHO). The results were compared with the National Drinking Water Quality Standard (NDWQS), 2005 and also with the World Health Organization (WHO, 2008) Drinking water quality guidelines, third edition and verified.

People from different walks of life have been interviewed for their knowledge, attitude and practice. For the purpose, fourteen key informants including skilled rainwater harvesters, health workers, user committee members, teachers and entrepreneurs, were interviewed with a help of a semi-structured checklists.

Sustainability assessment of rainwater harvesting system Sustainability of rainwater harvesting system was assessed based on four monitoring dimensions- technical, socio-environmental, financial and institutional for Water Supply Services (WSS) facilities (WaterAid, 2010). Each sustainability dimension is significantly governed by many parameters. The Figure 2 shows the conceptual framework for the study to assess the sustainability of Rainwater Harvesting System in Daugha VDC.

Each of the sustainability dimensions has been rated equally (Table 1), as all of them have similar level of potentiality and significance in making the system sustainable. Similarly, each core factor under each sustainability dimension includes various sub-factors. Each sub-factor is further given weightage based on the field findings and participatory discussions with the users. A RWH system, thus, was ranked as either 'Sustained' or 'Sustained but at risk' or 'Not sustained' projects (WaterAid, 2010).

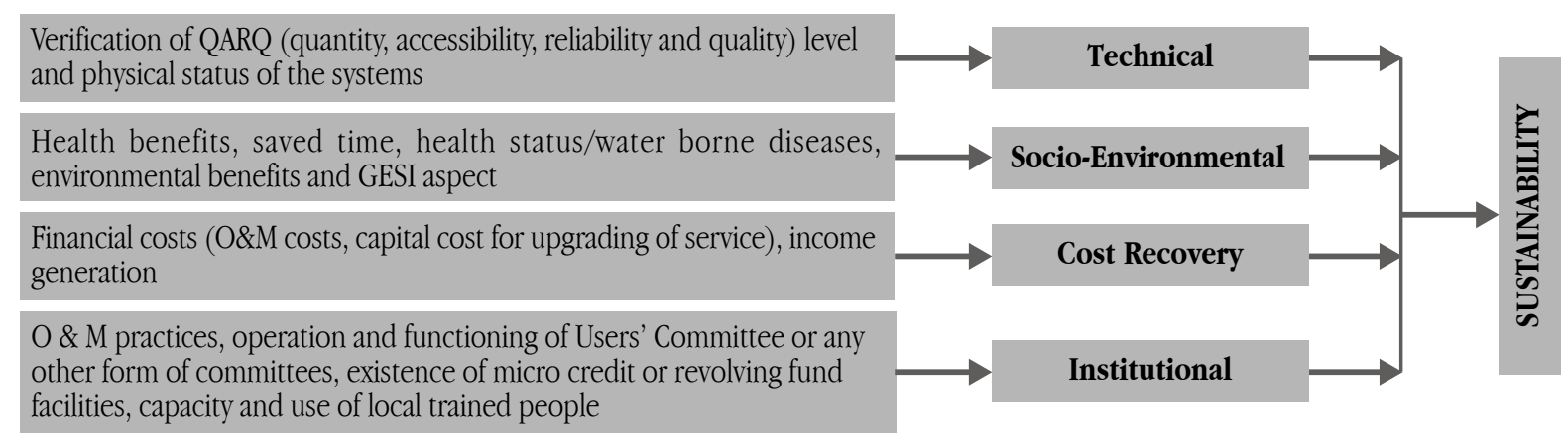

Figure 2 Conceptual framework of sustainable RWH system

Table 1 Sustainability weightage to the core factors

\begin{tabular}{llc}
\hline Sustainability Dimensions & Core factors to assess the Sustainability Dimensions & Weightage \\
\hline Technical (25) & Quantity of water (5) & 5 \\
& Quality of water (5) & 5 \\
& Accessibility/Time to fetch water (5) & 5 \\
& Reliability/Availability Months per year(5) & 5 \\
& Physical status of the system (5) & 5 \\
& Users' committee/Fund management Committee(5) & 5 \\
Institutional (25) & Village WASH Coordinating Committee functioning (5) & 5 \\
& Trained rainwater harvesters (5) & 5 \\
& Coordination and linkage of the committees (5) & 5 \\
& Transparency on loan disbursement, other expenditures, procurement and & 5 \\
& repayment of loan (5) & \\
& Water facility to the families and social equity (5) & 5 \\
Socio-environmental (25) & Improved health status, improved sanitary practices and improved & 5 \\
& hygiene behaviors (5) & \\
& Reduction in women's burden of fetching water, utilization of saved time in & 5 \\
& Income Generating activities, caring children and their education (5) & \\
& Gender and Social inclusion in the program (5) & 5 \\
& Environmental aspects and climate change effects on RWH systems (5) & 5 \\
& Managing O\&M fund for the RWH systems(10) & 10 \\
Managing system replacement fund (10) & 10 \\
Availability of local fund and its diversified use (5) & 5 \\
\hline
\end{tabular}




\section{Results and Discussion}

\section{Present context on rainwater harvesting}

After successful piloting of household level RWH system in 1996, up scaling and replication of the technology took place rapidly within and outside of Daugha. All nine wards of the VDC formed their RWH users' sub-committees under the lead of VDC level main committee and started implementing the project. The Rural Water Supply and Sanitation Project (RWSSP), in support of Finnish International Development Agency (FINNIDA), provided support to each household with two ferro-cement jars of 2,000-liter capacity along with the gutter system and the Corrugated Galvanized Iron (CGI) roofing sheets equivalent to $16.72 \mathrm{~m}^{2}$ area during the first round of implementation. Later on, the same ferro-cement jars of 6,500 liter capacity were designed and households were supported at the rate of one jar each. Families with better economic standing also started building bigger size stone masonry tanks to store enough water for the whole year. In this way, Daugha people started a huge and wonderful campaign to collect rainwater to meet their daily water demand. Altogether, 14 rainwater harvesters were trained by RWSSP in the VDC to support implementation of the project (Table 2). Families are still adding on such water harvesting tanks, whenever they have money to afford. The Table 2 shows number of various sized water collection tanks in the VDC.

\section{Sustainability of rainwater harvesting system}

In order to analyze the sustainability of the system four key sustainability dimensions i) technical, ii) socio-environmental, iii) institutional and iv) cost recovery were defined and the corresponding core factors and sub-factors contributing to these dimensions were identified. The core factors and sub-factors were given weightage following the Multi Criteria Analysis (MCA) method. The overall sustainability index of the RWH system installed in Daugha VDC for drinking purpose is presented in Table 4.

\section{Technical dimensions}

Under the 'Technical' dimension, five core factors of Quantity, Accessibility, Reliability, Quality (QARQ) and the physical status of the system have been considered (Fig. 3). The maximum points obtained in each core factor shall generate a regular polygon which indicates the smooth rollover of the polygon. All the core factors with maximum point mean that the considered dimension of sustainability is $100 \%$. Users were asked about access to the water supply services in terms of QARQ.

Table 2 Household level rainwater collection jars in the VDC

\begin{tabular}{clc}
\hline S. N. & Description & Number of jars/tanks \\
\hline 1. & 2,000-liter capacity jars & 916 \\
2. & 6,500-liter capacity jars & 236 \\
3. & Stone masonry of different size ranging from & 86 \\
& 15 to 85 cum & \\
\hline & Total & 1,238 \\
\hline & & (Source: Field Visit, 2014)
\end{tabular}

Regarding quantity, 21\% of the total interviewed households responded to have water sufficiency for all year round, whereas $79 \%$ of the households mentioned availability of water ranging from 5 to 10 months a year, based on the storage capacity and the number of users. Regarding accessibility to water, $50 \%$ households mentioned time saved up to one hour per trip, $26 \%$ mentioned from 1-2 hours saved per trip and $24 \%$ mentioned the time saved 2-3 hours per trip to fetch water. This comes to be average 6.35 hours of saved time per family per day. Similarly, reliability aspect shows that $21 \%$ of the total families interviewed have availability of water throughout the year, $6 \%$ have availability up to 10 months, and $19 \%$ have water availability up to 6 months, whereas remaining $21 \%$ have availability up to 5 months a year. In connection to the quality of stored rainwater in the jars, people have perceived it to be of good quality.

Quality test results (Table 3) obtained with the field kit test also indicate that most of the parameters are in the permissible range. There was large number ( 50 water samples) of samples found with bacteriological contamination. However, most families (82\%) use water for drinking after proper boiling.

\section{Socio-environmental sustainability}

Under "Socio-Environmental" dimension of rainwater sustainability, the core factors were identified as improved sanitary practices, health status and hygiene behaviors, water facility to the families and social equity, gender and social inclusion in the program, reduction in women's burden of fetching water and environmental aspects and the climate change effects (Fig. 4). The findings indicate significant progress on that front. All 104 households were found to be reasonably aware of the importance of sanitation and hygiene. The extent of open defecation seems to have gone down drastically in the VDC. More than $80 \%$ of the households in the VDC reported to have toilets in their homestead. Similar trend was noticed in case of hand-washing with soap during critical times. Decline in incidences of waterborne diseases, such as diarrhea, dysentery, typhoid were reported by nearly $90 \%$ of the households. Regarding water facility to the families and social equity, it is noteworthy that no discrimination against the caste and economic hierarchy existed

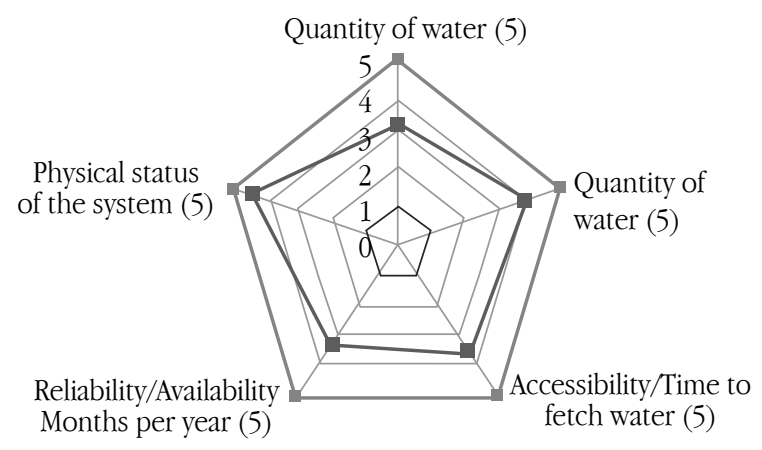

Figure 3 Technical dimensions for rainwater harvesting sustainability 
in the VDC, as all the household interviews and key informant level interviews confirmed this fact. Regarding the gender and social inclusion, there has been a remarkable positive change. Women, because of their saved time from fetching water, have started participating in various development activities and have formed various Self Help Women Groups (SHWGs) such as mothers' groups and women groups in the village. They have started taking part in educational and infrastructural development interventions hand in hand with male counterparts. This equally implies in case of Pro-poor and Dalit families as well. Dalits have been found representing in all the groups and committees on a proportionate basis. In this way, the rainwater harvesting program in Daugha has proved to be the key milestone in improving the Gender Equity and Social Inclusion (GESI) in development. Similarly, the respondents revealed that there are environment related issues like reduced rainfall, which people have been experiencing over the period of about two decades. Briefly, it can be summed that rainwater harvesting has been proved as the most appropriate and the best option in the given context and is the most suitable adaptation method to the given environment.

\section{Institutional dimensions}

Core factors such as functioning of user's committee/fund management committee, functioning of Village WASH Coordinating Committee (VWASHCC) in the VDC, skills and capacity of trained rainwater harvesters, transparency about the fund and linkages with other government and non-government organizations in the district were identified to represent institutional dimension (Fig. 5). Regarding functioning of users committee, the findings indicate that more than $90 \%$ of the respondents at household level affirmed that it is virtually inactive at present. The users committee remained active during implementation of the project and the same committee has been made responsible for handling the revolving funds, commonly known as fund management committee. Related to transparency of the system, knowledge among the respondents about the total fund, about its deposition and uses was found to be very low as only $25 \%$ of the respondents have know-how about it. Information on the views of the respondents about service rendered by the locally trained rainwater harvesters (mistri) was solicited. Among the total, $75 \%$ of the respondents mentioned their performances as good. All 14 trained rainwater harvesters

Table 3 Water quality test result

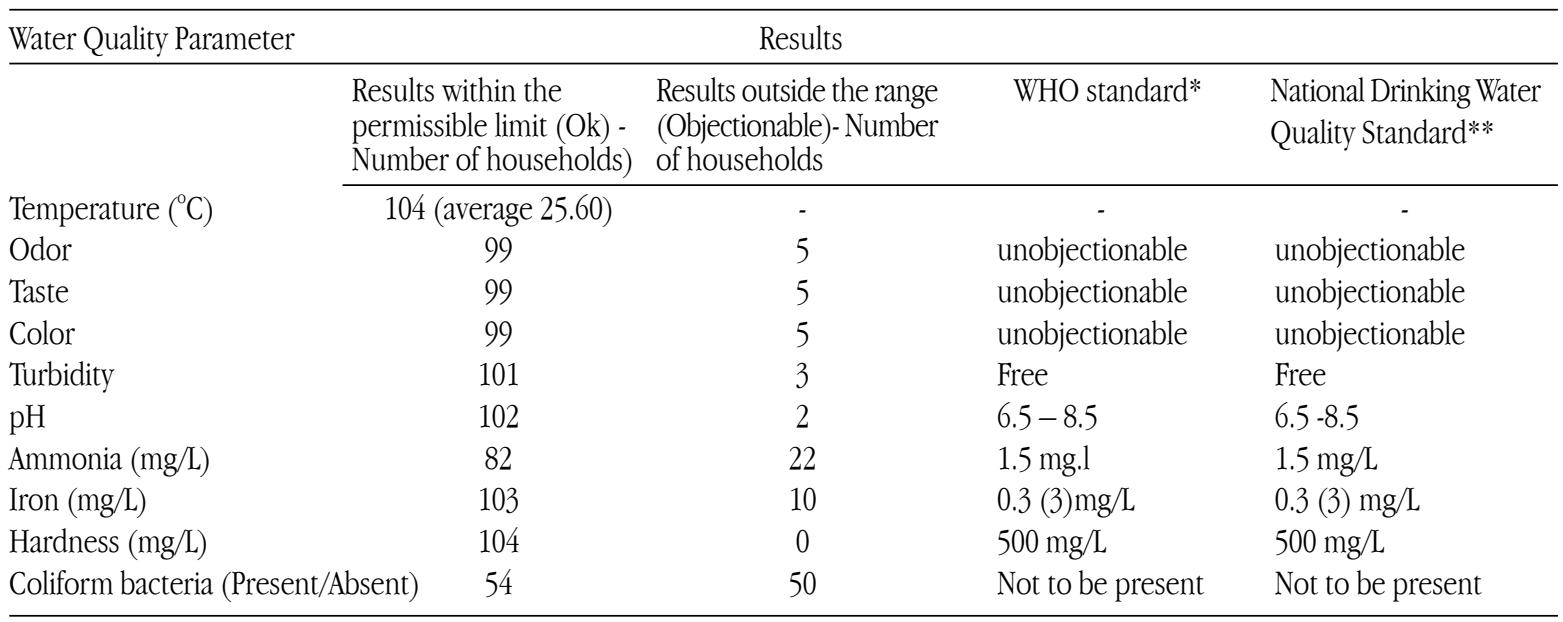

*WHO (2008); **GoN (2005)

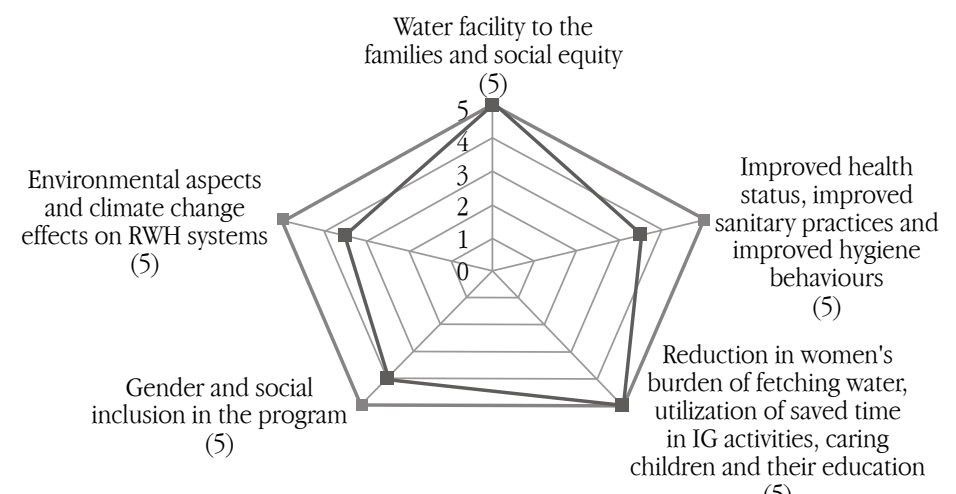

(5)

Figure 4 Socio-environmental dimensions of rainwater harvesting sustainability 
remain mostly outside of the village implementing RWH systems in different parts of the country. Some of them are also engaged in installing such systems in Tehari Gadhwal area of Uttarakhand Pradesh (KII, 2014). However, 25\% of respondents of the households interviewed mentioned that service is rather difficult to avail when required by the villagers, as they remain mostly out of the village. Similarly, regarding functioning of Village Water, Sanitation and Hygiene Coordination Committee (VWASHCC), though active in the VDC related to WASH coordination issues, it is constrained by physical facilities and financial resources for

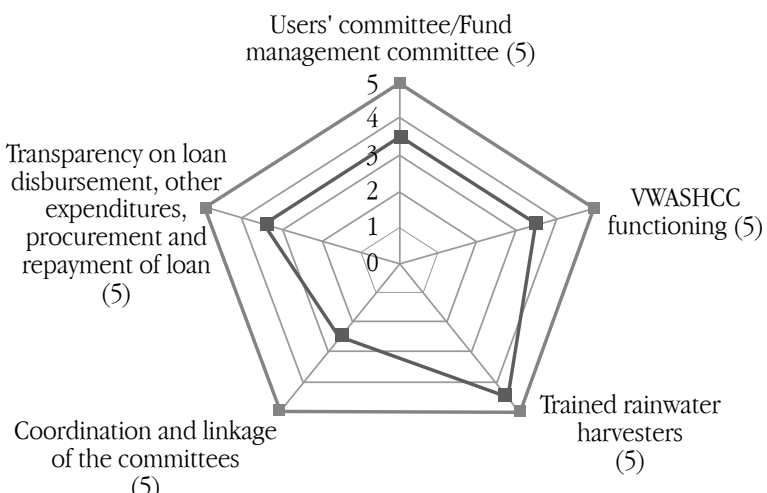
(5)

Figure 5 Institutional dimension of rainwater harvesting sustainability its effective regular functioning.

\section{Cost recovery}

Under "Cost Recovery", the core factors identified are managing funds for $\mathrm{O} \& \mathrm{M}$ of RWH systems, managing replacement fund of systems and diversified use of the local fund (Fig. 6). Cost recovery in case of RWH system is the full responsibility of the concerned households. On overage, the cost needed for annual repair and maintenance of the system was calculated to be NRs. 2,000.00 per household (household survey). It basically includes the cost of

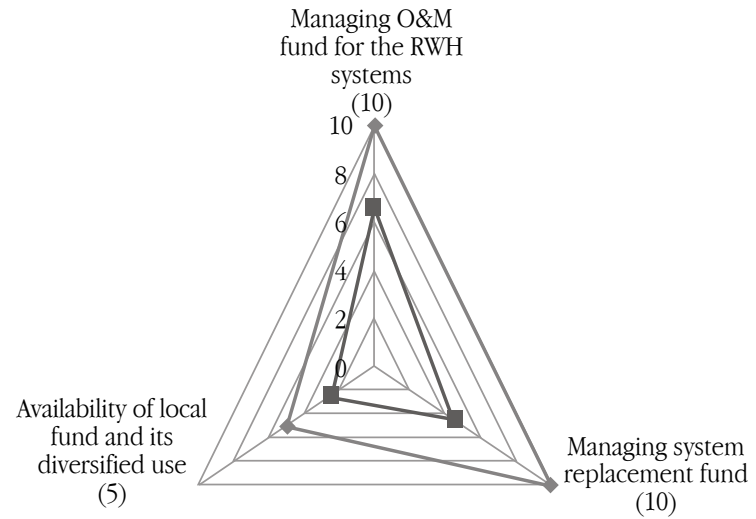

Figure $\mathbf{6}$ Cost recovery dimension of rainwater harvesting sustainability

Table 4 Overall sustainability of the rainwater harvesting system

\begin{tabular}{|c|c|c|c|c|c|}
\hline $\begin{array}{l}\text { Sustainability } \\
\text { dimensions }\end{array}$ & $\begin{array}{l}\text { Core factors to assess the } \\
\text { sustainability dimensions }\end{array}$ & Weightage & $\begin{array}{l}\text { Allocated } \\
\text { based on field } \\
\text { survey }\end{array}$ & $\begin{array}{l}\text { Individual } \\
\text { cumulative } \\
\text { score }\end{array}$ & $\begin{array}{l}\text { Percentage } \\
\quad(100 \%)\end{array}$ \\
\hline Technical (25) & $\begin{array}{l}\text { Quantity of water (5) } \\
\text { Quality of water (5) } \\
\text { Accessibility/Time to fetch water (5) } \\
\text { Reliability/Availability Months per year(5) } \\
\text { Physical status of the system (5) }\end{array}$ & $\begin{array}{l}5 \\
5 \\
5 \\
5 \\
5\end{array}$ & $\begin{array}{l}3.3 \\
4 \\
3.6 \\
3.3 \\
4.5\end{array}$ & 18.7 & 74.8 \\
\hline Institutional (25) & $\begin{array}{l}\text { Users' committee/Fund management Committee (5) } \\
\text { VWASHCC functioning ( } 5 \text { ) } \\
\text { Trained rainwater harvesters (5) } \\
\text { Coordination and linkage of the committees (5) } \\
\text { Transparency on loan disbursement, other } \\
\text { expenditures, procurement and repayment of loan }(5)\end{array}$ & $\begin{array}{r}5 \\
5 \\
5 \\
5 \\
\\
\text { (5) } 5\end{array}$ & $\begin{array}{l}3.0 \\
3.5 \\
4.5 \\
2.5 \\
3.5\end{array}$ & 17 & 68 \\
\hline Socio-environmental (25) & $\begin{array}{l}\text { Water facility to the families and social equity (5) } \\
\text { Improved health status, improved sanitary practices } \\
\text { and improved hygiene behaviors (5) } \\
\text { Reduction in women's burden of fetching water, } \\
\text { utilization of saved time in IG activities, caring children } \\
\text { and their education (5) } \\
\text { Gender and Social inclusion in the program (5) } \\
\text { Environmental aspects and climate change effects on } \\
\text { RWH systems (5) }\end{array}$ & $\begin{array}{l}5 \\
5 \\
5 \\
\\
5 \\
5\end{array}$ & $\begin{array}{c}5 \\
3.5 \\
5 \\
\\
4 \\
3.5\end{array}$ & 21 & 84 \\
\hline Cost Recovery (25) & $\begin{array}{l}\text { Managing O\&M fund for the RWH systems(10) } \\
\text { Managing system replacement fund (10) } \\
\text { Availability of local fund and its diversified use (5) }\end{array}$ & $\begin{array}{l}10 \\
10 \\
5\end{array}$ & $\begin{array}{l}6.5 \\
5.0 \\
2.5 \\
\text { Overall Su}\end{array}$ & $\begin{array}{l}14.0 \\
\text { Istainability S }\end{array}$ & $\begin{array}{r}56 \\
\text { ore } 70.7\end{array}$ \\
\hline
\end{tabular}

Field observation and Household Interview (2014)

\section{璃 TU-CDES}


chlorination at frequent intervals for maintaining water quality, cost of white cement or lime to paint two coats both inside and outside the jars, some nails to repair and properly fix the gutter system, few High Density Polyethylene/Galvanized Iron (HDPE/GI) fittings (occasional), and mosquito net to replace in the jar lid. However, to add one more jar of 2,000-liter capacity, it requires an amount nearly equivalent to NRs. 15,000.00, excluding labor cost.

The major question here is: how and where will the money come from to recover these costs? Have RWH systems created opportunities for the families to earn money at least equivalent to the above-mentioned level? Have people realized and started utilizing their time and energy saved through implementation of RWH systems, which otherwise would have been spent on fetching water. A simple calculation showed that saving time equivalent to 6.35 hour per day per family on average for a period of 7.2 months (average storage duration) per year saves about 173 person days of labor. This is substantial period of time that can be utilized to earn money either working as a wage labor, working on farm productions like vegetable farming, rearing goat, promoting poultry, starting own small business or starting small scale cottage industry. Moreover, there exists a revolving fund originally established with support from the then ongoing European Union (EU) supported Gulmi Arghakhanchi Rural Development Project (GARDEP) worth NRs. 900,000.00 in the VDC focusing to increase the Water Sanitation and Hygiene (WASH) facilities, which is also used for various purposes in the village. The fund created in 1999, mainly targets the poor families, who were not able to upgrade and upscale the RWH system in spite of its beneficial impacts on the households and community as a whole, with a loan (KII, 2014). In addition, this fund was also agreed to lend for diversified uses in the VDC rather than just keeping ideally in the bank. This had created an avenue for the people to start their own small business. The fund is still maintained in the VDC and the amount has reached NRs. 2.5 million as of 2014.

\section{Conclusion}

The above results indicates that the RWH project in Daugha VDC is a 'sustained but at risk' category project with reference to the sustainability figures as prescribed by WaterAid. In order to be a sustained project, the project must obtain equal to or more than $70 \%$ score in all four sustainability dimensions individually. But, in this case, institutional and cost recovery dimensions of sustainability draw the project at risk from sustainable point of view. However, the technical and the socio-environmental dimensions have proved to be strong enough to bring the whole project in category of two, i.e. "sustained but at risk". In Daugha VDC, local people have taken rainwater harvesting as their inherent culture, which itself shows high social and environmental acceptance for the system. It is now very clear from the above results that an urgent step towards the improvement of the institutional and cost recovery aspects of the project is needed.

\section{Acknowledgements}

The authors would like to express their sincere gratitude to the local people of Daugha VDC for sparing their time for the household interviews. The authors would also like to thank all the persons who were directly or indirectly involved in the study, may it be during field works or during various phases of study.

\section{References}

Cochrane, W. G. (1977). Sampling techniques. $3^{\text {rd }}$ edition. John Wiley and Sons. New York. United States of America.

Dey, P., \& Sikka, A. (2010). Watre Conservation Through Rainwater Harvesting. The IUPJournal of Soil and Water Sciences, 3(1), 61-71.

GoN (2005). National Drinking Water Quality Standards, 2005Implementation Directives for National Drinking Water Quality Standards 2005. Ministry of Physical Planning and Works. Government of Nepal.

Julius, J., Prabhavathy, R.A., \& Ravikumar, G., August-2013. Rainwater Harvesting (RWH)-A Review. International Journal of Scientific E Engineering Research, 4(8), 276-282.

RWSSP (1995). District Water Supply and Sanitation Development Plan, Gulmi. Final. Butwal: Rural water Supply and Sanitation Project, Lumbini.

WaterAid (2010). Long Term Sustainability Monitoring, WaterAid's Experience in Nepal. WaterAid, Nepal.

WHO (2008). Guidelines for drinking water quaility. $4^{\text {th }}$ Edition. World Health Oranization. ISBN: 9789241547611

WHO/UNICEF (2012). Joint Monitoring Programme (JMP) for Water Supply and Sanitation: Progress and Sanitation and Drinking Water. Geneva. 